\title{
LETTER
}

\section{Fentanyl- and midazolam-induced coma each influence days of mechanical ventilation and 28-day mortality}

\author{
Maged Tanios ${ }^{1}$, Huan Mark Nguyen ${ }^{2}$, Quang A. Le ${ }^{2}$, Hyunsoon Park ${ }^{3}$ and John W. Devlin ${ }^{4,5^{*}}$ (1)
}

(C) 2021 Springer-Verlag GmbH Germany, part of Springer Nature

\section{Dear Editor,}

Guidelines suggest an assessment-driven, analgesia/ analgosedation, protocol-based approach for pain and sedation in critically ill adults [1]. While coma associated with benzodiazepine and propofol has been shown to prolong the duration of mechanical ventilation and increase mortality [2], the association between comarelated to continuous opioid therapy (e.g., fentanyl) on days of mechanical ventilation and mortality remain unclear [1]. Twelve analgosedation randomized controlled trials (RCT) have compared continuous opioids (remifentanil $n=10$, morphine/fentanyl $n=2$ ) to either an 'as needed' analgesic-first different opioid and 'as needed' benzodiazepine/propofol sedation $(n=5)$ OR scheduled benzodiazepine/propofol therapy and 'as needed' opioid therapy $(n=6)$ [3]. Among these latter six RCTs, only one RCT used a protocolized approach to maintain patients at light sedation [Richmond Agitation Sedation Scale $($ RASS $)=-2-0$ ] and conduct spontaneous breathing trials [4].

In this trial approved by our Institutional Review Board, we randomized 86 mechanically ventilated adults (age 65 years, male 53\%, APACHE-2 score 25, medical $79 \%)$ to receive continuous fentanyl $(\mathrm{CF})+$ 'as needed' propofol $(n=27)$ OR continuous midazolam $(\mathrm{CM})+$ 'as needed' fentanyl $(n=59)$. Among the $59 \mathrm{CM}$ patients, 28 were managed with protocolized sedation only and 31 were managed with both protocolized sedation and daily sedation interruption. Only 5 CF patients required

*Correspondence: j.devlin@neu.edu

${ }^{4}$ School of Pharmacy, Northeastern University, 360 Huntington Ave, 140 TF 216D, Boston, MA 02115, USA

Full author information is available at the end of the article propofol; it was weaned off in four patients in $<6 \mathrm{~h}$. Daily propofol exposure in the CF patients was converted to midazolam dose equivalents.

Age, APACHE-II score, coma (RASS $=-4$ or -5 ) occurrence and its duration, days free of mechanical ventilation at 28 days, and 28 -day mortality were not statistically different between the CF and CM groups (Table 1). Compared to the CM group, patients in the CF group received significantly more daily fentanyl $(P=0.05)$ and significantly less sedation $(P<0.001)$. On coma (vs. no coma) days, across both CF and CM groups, daily use of fentanyl (median 972.4 vs. $224.6 \mathrm{mcg}, P=0.02$ ) and midazolam (median $14.2 \mathrm{vs} .3 .3 \mathrm{mg}, P=0.009$ ) were greater on coma days. Among patients who developed coma, the presence of $\geq 1$ baseline neurologic condition was similar between CF (vs. no CM) [3(33.3\%) vs.7(26.9\%) $P=0.54$ ) groups.

Separate multivariable logistic regression models controlling for age, APACHE-II score, daily fentanyl, daily gabaminergic sedation exposure, CF (vs. CM) group allocation, and coma occurrence was constructed for each clinical outcome (i.e., days free of mechanical ventilation in 28-days and mortality in 28-days). We found coma was the only variable independently associated with more days of mechanical ventilation $(\mathrm{OR}=2.0$, 95\% CI $1.43-23.1, \quad P=0.02)$ or greater mortality $(\mathrm{OR}=5.9,95 \% \mathrm{CI} 1.4-25.5 ; P=0.01)$ at 28 -days regardless of whether patients were allocated to the CF or CM groups.

Our results suggest the effect of medication-associated coma on days spent on mechanical ventilation or 28-day mortality is similar regardless of whether the coma is related to an analgosedation or gabaminergic sedative management approach. Until future 
Table 1 Comparison of baseline, ICU and post-ICU outcomes between continuous fentanyl and midazolam groups

\begin{tabular}{|c|c|c|c|}
\hline Variable & $\begin{array}{l}\text { Continuous Fentanyl } \\
\text { Group } N=27\end{array}$ & $\begin{array}{l}\text { Continuous Midazolam } \\
\text { Group } N=59\end{array}$ & $P$ value \\
\hline Age; mean $\pm S D$ & $65.6 \pm 15.8$ & $65.1 \pm 17.2$ & 0.89 \\
\hline $\mathrm{APACHE}-\|$ score; mean $\pm \mathrm{SD}$ & $25.7 \pm 8.5$ & $24.7 \pm 7.9$ & 0.59 \\
\hline Coma ever during ICU stay; $N(\%)$ & $9(33.3 \%)$ & $26(44.8 \%)$ & 0.32 \\
\hline Time spent in coma on a day coma occurred (hours); median (IQR) & $3.8(1.3,6.6)$ & $1.9(1,4.2)$ & 0.22 \\
\hline Daily ICU fentanyl exposure (mcg); median (IQR) & $782(400,1512)$ & $187(65-432)$ & 0.02 \\
\hline Daily ICU midazolam equivalent exposure (mg); median (IQR) & $0(0,2.7)$ & $16.4(6-33)$ & $<0.001$ \\
\hline Days free of mechanical ventilation 28 days after randomization; median (IQR) & $24(23-26)$ & $24(20-26)$ & 0.95 \\
\hline Mortality 28 days after randomization; N (\%) & $9(33.3 \%)$ & $10(17 \%)$ & 0.09 \\
\hline
\end{tabular}

prospective research is conducted to confirm our results, clinicians should optimize strategies to maintain patient wakefulness and reduce patient-ventilator asynchrony in mechanically ventilated adults and consider alternatives to opioid and gabaminergic sedatives including non-opioid analgesics, dexmedetomidine, and inhaled anesthetics [5] (Table 1).

\section{Author details}

1 Division of Pulmonary and Critical Care Medicine, Long Beach Memorial Hospital, Long Beach, CA, USA. ${ }^{2}$ Department of Pharmacy Practice and Administration, Western University of Health Sciences, Pomona, CA, USA. ${ }^{3}$ Department of Nursing, Long Beach Memorial Hospital, Long Beach, CA, USA. ${ }^{4}$ School of Pharmacy, Northeastern University, 360 Huntington Ave, 140 TF 216D, Boston, MA 02115, USA. ${ }^{5}$ Division of Pulmonary and Critical Care Medicine, Brigham and Women's Hospital, Boston, MA, USA.

\section{Declarations}

\section{Conflicts of interest}

All authors declare no conficts of interest.

\section{Publisher's Note}

Springer Nature remains neutral with regard to jurisdictional claims in published maps and institutional affiliations.

Accepted: 21 April 2021

Published online: 5 May 2021

\section{References}

1. Devlin JW, Skrobik Y, Gelinas C, Needham DM, Slooter AJC, Pandharipande PP, Watson PL, Weinhouse GL, Nunnally ME, Rochwerg B, Balas $M C$, van den Boogaard M, Bosma KJ, Brummel NE, Chanques G, Denehy L, Drouot X, Fraser GL, Harris JE, Joffe AM, Kho ME, Kress JP, Lanphere JA, McKinley S, Neufeld KJ, Pisani MA, Payen JF, Pun BT, Puntillo KA, Riker RR, Robinson BRH, Shehabi Y, Szumita PM, Winkelman C, Centofanti JE, Price C, Nikayin S, Misak CJ, Flood PD, Kiedrowski K, Alhazzani W (2018) Clinical practice guidelines for the prevention and management of pain, agitation/sedation, delirium, immobility, and sleep disruption in adult patients in the ICU. Crit Care Med 46:e825-e873

2. Girard TD, Kress JP, Fuchs BD, Thomason JW, Schweickert WD, Pun BT, Taichman DB, Dunn JG, Pohlman AS, Kinniry PA, Jackson JC, Canonico AE, Light RW, Shintani AK, Thompson JL, Gordon SM, Hall JB, Dittus RS, Bernard GR, Ely EW (2008) Efficacy and safety of a paired sedation and ventilator weaning protocol for mechanically ventilated patients in intensive care (Awakening and Breathing Controlled trial): a randomised controlled trial. Lancet 371:126-134

3. Wang C, Mao Y, Zhao L, Ma B (2019) The impact of analgosedation on mortality and delirium in critically ill patients: a systematic review and meta-analysis. Intensive Crit Care Nurs 54:7-14

4. Tanios M, Nguyen HM, Park H, Mehta S, Epstein SK, Yousseff F, Beltran A, Flores G, Sidhom R, Sehgal R, Leo J, Devlin JW (2019) Analgesia-first sedation in critically ill adults: A U.S. pilot, randomized controlled trial. J Crit Care 53:107-113

5. Chanques G, Constantin JM, Devlin JW, Ely EW, Fraser GL, Gélinas C, Girard TD, Guérin C, Jabaudon M, Jaber S, Mehta S, Langer T, Murray MJ, Pandharipande P, Patel B, Payen JF, Puntillo K, Rochwerg B, Shehabi Y, Strøm T, Olsen TH, Kress JP (2020) Analgesia and sedation in patients with ARDS. Intensive Care Med 46:2342-2356 